\title{
Hidrolisado de mucosa intestinal de suínos em substituição ao plasma sangüíneo em dietas para leitões de 21 a 49 dias $^{1}$
}

\author{
Anderson Corassa ${ }^{1}$, Darci Clementino Lopes $^{2}$, Sérgio de Miranda Pena ${ }^{1}$, Letícia Silva de \\ Freitas $^{1}$, Graciane de Miranda Pena ${ }^{3}$
}

\footnotetext{
1 Programa de Pós-Graduação em Zootecnia - UFV.

2 Departamento de Zootecnia - UFV.

${ }^{3}$ Curso de Graduação em Zootecnia - UFV.
}

RESUMO - Um experimento foi conduzido para avaliar o efeito da substituição parcial ou total do plasma sangüíneo por hidrolisado de mucosa intestinal de suínos (HI) em dietas para leitões de 21 a 49 dias. Cento e quarenta leitões desmamados aos 21,7 $\pm 2,9$ dias com peso médio de 5,54 $\pm 0,65 \mathrm{~kg}$ foram distribuídos em um delineamento experimental de blocos ao acaso, com cinco tratamentos, sete repetições e quatro animais por unidade experimental. $\mathrm{O}$ experimento foi dividido nas fases de 21 a 35 dias e de 36 a 49 dias de idade. Os tratamentos consistiram de uma dieta com plasma e de quatro dietas contendo diferentes níveis dos produtos HI 50 e HI 62 em substituição ao plasma. A substituição parcial ou total do plasma pelos produtos HI 50 e HI 62 não resultou em diferenças no consumo médio diário, no ganho de peso médio diário e na conversão alimentar de leitões nos períodos avaliados. Os pesos absoluto e relativo das vísceras funcionais não foram afetados pelos tratamentos. Não houve efeito das dietas sobre as características de integridade intestinal no duodeno, jejuno e íleo de leitões com 35 dias de idade. Os produtos HI 50 e HI 62 podem substituir total ou parcialmente o plasma em rações para leitões de 21 a 49 dias de idade sem efeitos significativos.

Palavras-chave: hidrolisado de mucosa intestinal de suínos, leitões, morfologia intestinal, plasma

\section{Hydrolyzed of intestinal mucosa of swine in substitution to blood plasma in diets of pigs from 21 to 49 days}

\begin{abstract}
A trial was conduced to evaluate the effect partial or total substitution of blood plasma for hydrolyzed of intestinal mucosa of swine (HI) in diets of pigs from 21 to 49 days of age. A total of 140 piglets weaned at $21.7 \pm 2.9$ days of age with average weight of $5.54 \pm 0.65 \mathrm{~kg}$ were allotted to a randomized experimental block design, with five treatments, seven replications of four animals per experimental unit. The experiment was divided in the phases from 21 to 35 days and from 36 to 49 days of age. The treatments consisted of a diet with plasma and four diets with different levels of HI 50 and HI 62 products in substitution of plasma. The partial or total plasma substitution for HI 50 and HI 62 products did not result in differences for average daily feed intake, average daily weight gain and feed:gain ratio of piglets in the evaluated periods. The absolute and relative weight of the functional viscera was not affected by treatments. There were not effects of the treatments on the characteristics of intestinal integrity in the duodenum, jejunum and ileum of piglets with 35 days of age. The products HI 50 and HI 62 could substitute total or partially the plasma in diets of pigs from 21 to 49 days of age without significant effects.
\end{abstract}

Key Words: hydrolyzed of intestinal mucous membrane of swine, intestinal morphology, piglets, plasma

\section{Introdução}

O desmame tem sido apontado como uma das fases mais críticas de um sistema de produção de suínos. A mudança de uma dieta líquida para uma dieta sólida, a baixa capacidade de digerir e absorver nutrientes, alterações na morfologia da mucosa intestinal, entre outros fatores causa estresse e tornam-se desafio para os pesquisadores da área de nutrição de suínos (Bertol et al., 2001; Scandolera et al., 2005; Teixeira et al., 2005).
Sabe-se que uma alternativa para amenizar o desafio nutricional imposto pelo desmame é o uso de dietas complexas contendo leite em pó e plasma sanguíneo como fontes de proteína de alta qualidade. Entretanto, esses ingredientes muitas vezes oneram o custo das rações (Figueiredo et al., 2003).

Nesse sentido, o hidrolisado de mucosa intestinal de suínos (HI) aparece como opção a ser estudada, pois é considerado fonte rica em peptídeos e aminoácidos livres e se mostra como um produto de proteína altamente digestível 
em dietas para leitões (Córdoba et al., 2000). Subproduto da extração de heparina em intestino de suínos, o HI é uma fonte de proteína de alta qualidade e tem melhorado os resultados de desempenho de leitões à desmama (Bregendahl et al., 1998).

Como o HI é uma fonte de proteína hidrolisada, deve ter mais aminoácidos de cadeia curta e proporcionar efeitos positivos sobre a absorção de aminoácidos e na produção de hormônios pancreáticos (Nutra-Flo, 2004). Os aminoácidos no HI são encontrados principalmente na formas livre ou peptídeos (65 e 35\%, respectivamente), apresentando-se assim como produto de proteína de alta digestibilidade (Ângulo et al., 2001).

Em estudo para avaliar o nível de inclusão de HI em dietas para leitões à desmama, Zimmerman \& Sparks (1996) verificaram que é possível incluir HI em $5 \%$ da dieta em substituição ao farelo de soja sem prejudicar o desempenho dos animais. No mesmo trabalho, foi descrito que altas concentrações de HI poderiam reduzir a energia e/ou aumentar a concentração de sódio prejudicando o desempenho dos animais.

Informações acerca da utilização de hidrolisado intestinal são raras, especialmente sob condições brasileiras. Por isso, objetivou-se com este estudo avaliar o efeito da substituição parcial ou total do plasma por hidrolisado de mucosa intestinal de suínos na dieta sobre o desempenho, a alometria e a morfometria intestinal de leitões de 21 a 49 dias de idade.

\section{Material e Métodos}

O experimento foi conduzido no Setor de Suinocultura do Departamento de Zootecnia da Universidade Federal de Viçosa, MG, para avaliação de respostas sobre o desempenho e a morfologia do intestino delgado. Foram utilizados 140 leitões desmamados aos 21,7 $\pm 2,9$ dias com peso inicial de 5,54 $\pm 0,65 \mathrm{~kg}$ em um delineamento experimental de blocos ao acaso, com cinco tratamentos, sete repetições e quatro animais por unidade experimental. Foram adotados o peso, o sexo e o parentesco dos leitões como critérios na formação dos blocos. Cada unidade experimental foi formada por dois machos castrados e duas fêmeas.

O experimento foi dividido em duas fases (pré-inicial 1, de 21 a 35 dias, e pré-inicial 2, de 36 a 49 dias) nas quais foram utilizadas dietas que atenderam no mínimo as exigências nutricionais dos animais de acordo com as Tabelas Brasileiras para Aves e Suínos de Rostagno (2005). Em cada fase os tratamentos foram constituídos de dietas isoprotéicas, isoenergéticas e isolisínicas. Os tratamentos consistiram de uma dieta com plasma sangüíneo (controle) e quatro dietas contendo diferentes níveis dos produtos hidrolisado de mucosa intestinal de suínos com 62 e 50\% de $\mathrm{PB}$, registrados comercialmente como Palbio $62 \mathrm{SP}^{\circledR} \mathrm{e}$ Palbio $50 \mathrm{RD}^{\circledR}$ e identificados neste estudo como HI 62 e HI 50, conforme Tabela 1. Os valores de proteína bruta $(\%)$, energia metabolizável ( $\mathrm{kcal} / \mathrm{kg})$, lisina, metionina + cistina, treonina e triptofano utilizados na matriz nutricional dos produtos HI 62 e HI 50 foram: 62; 2350; 4; 1,$61 ; 2,98 ; 0,39$ e $50 ; 3020 ; 2,95 ; 3,99 ; 1,91 ; 0,39$, respectivamente, considerando valores de aminoácidos digestíveis (\%). As composições centesimais e nutricionais das dietas experimentais das fases pré-inicial 1 e 2 estão dispostas nas Tabelas 2 e 3.

Após a desmama, os animais foram transportados para a sala de creche de alvenaria, com piso de concreto, forro de madeira rebaixado, janelas de vidro tipo basculante, dotadas de gaiolas metálicas suspensas, medindo 1,60 × 1,0 $\times 0,56 \mathrm{~m}$, com piso em plástico expandido e com as laterais de tela metálica, dotadas de comedouros semi-automáticos e bebedouros tipo chupeta.

Para avaliação do desempenho, foram utilizadas as variáveis: consumo de ração médio diário (CRMD), ganho de peso médio diário (GPMD) e conversão alimentar (CA). Para mensuração desses parâmetros foram realizadas pesagens dos animais, dos comedouros e das sobras de ração no início do experimento e no final de cada fase $\left(21^{\circ}, 35^{\circ} \mathrm{e}\right.$ 49 o dias). O controle do consumo e do desperdício das

Tabela 1 - Níveis de inclusão (\%) de plasma e hidrolisado de mucosa intestinal de suínos (HI) nas dietas experimentais

Table 1 - Levels of inclusion (\%) of plasma and hydrolyzed of intestinal mucosa of swine $(\mathrm{HI})$ in the experimental diets

\begin{tabular}{|c|c|c|c|c|}
\hline \multirow[t]{2}{*}{$\begin{array}{l}\text { Ingrediente } \\
\text { Ingredient }\end{array}$} & \multicolumn{4}{|c|}{$\begin{array}{c}\text { Tratamento } \\
\text { Treatment }\end{array}$} \\
\hline & Plasma & $\begin{array}{c}\text { Plasma }+ \\
\text { HI } 62\end{array}$ & HI 62 & $\begin{array}{l}\text { Plasma }+ \text { HI } 50 \\
\text { HI } 50\end{array}$ \\
\hline
\end{tabular}

Pré-inicial 1

Pre-initial 1

\begin{tabular}{llllll}
\hline Plasma & 5 & 2 & - & 3 & - \\
HI 62 & - & 3 & 3 & - & - \\
HI 50 & - & - & - & 5 & 5
\end{tabular}

Pré-inicial 2

Pre-initial 2

\begin{tabular}{lccccc}
\hline Plasma & 5 & 1,5 & - & 1,5 & - \\
HI 62 & - & 1,5 & 3 & - & - \\
HI 50 & - & - & - & 5 & 5 \\
\hline
\end{tabular}

HI 62, HI 50 = hidrolisado de mucosa intestinal de suínos com 62 e 50\% $\mathrm{HI} 62, \mathrm{HI} 50=$ hidrolis
$\mathrm{PB}$, respectivamente.

HI 62, HI 50 = hydrolyzed of intestinal mucosa of swine with 62 and $50 \%$ CP, respectively. 
Tabela 2 - Composições centesimal dos ingredientes e nutricional das dietas experimentais utilizadas na fase pré-inicial 1 (21 a 35 dias) Table 2 - Ingredient percentage and nutritional compositions of the experimental diets in the pre-starter phase 1 (21 to 35 days)

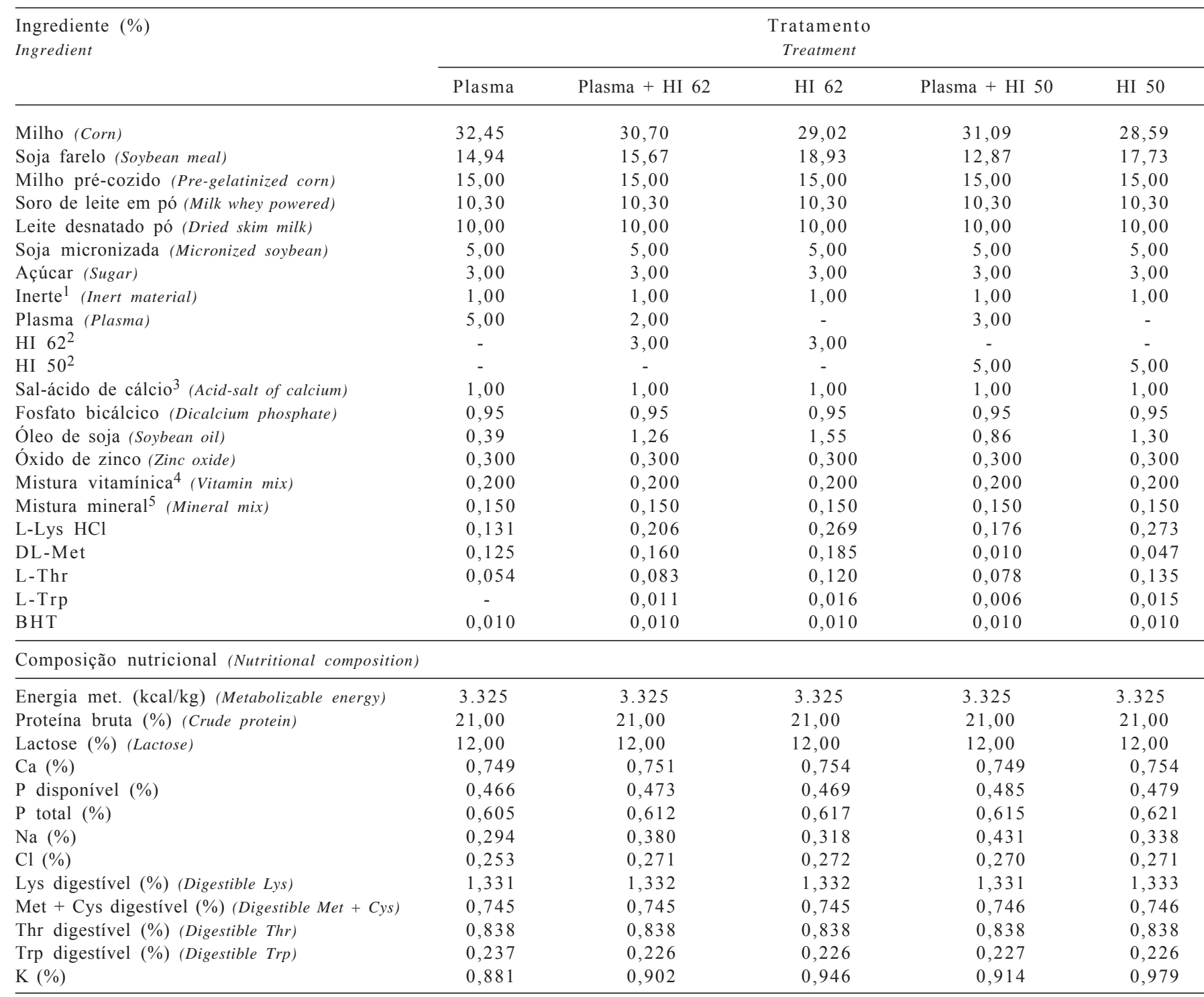

${ }^{1}$ Inerte foi substituído parcialmente por cloreto de colina e lincomicina (Inert was partially replaced by chloride of hill and lyncomicin).

2 HI 62 e HI 50: Hidrolisado da mucosa intestinal de suínos - Palbio 62 SP$^{\circledR}$ e Palbio 50 RD ${ }^{\circledR}$ - Metachem Ind. Com. Ltda. (hydrolyzed of intestinal mucosa of swine - Palbio $62 S P^{\circledR}$ and Palbio 50 RD ${ }^{\circledR}$ - Metachem Ind.Com.Ltda.).

${ }^{3} \mathrm{Ca}$ - 25\%; P - 6\%; ácido orto-fosfórico, fórmico, acético, propiônico, cítrico - Calprona PP6 ${ }^{\circledR}$ - Metachem Ind. Com. Ltda. (Orto-fosforic acid, formic acid, acetic acid, propionic acid, citric acid - Calprona PP6®-Metachem Ind. Com. Ltda).

${ }^{4}$ Composição por kg de produto (Composition for product kg): vit. A - $6.000 .000 \mathrm{UI}$; vit. D3 - $1.500 .000 \mathrm{UI}$; vit. E - $15.000 \mathrm{UI}$; vit. K3 - $1.500 \mathrm{mg}$; vit. B1 1.350 mg; vit. B2 - 4.000 mg; vit. B6 - 2.000 mg; vit. B12 - 20.000 mg; ácido nicotínico (nicotinic acid) - 20.000 mg; ácido pantotênico (pantothenic acid) $1.350 \mathrm{mg}$; biotina (biotin) - $80 \mathrm{mg}$; ácido fólico (folic acid): $600 \mathrm{mg}$; Se - $300 \mathrm{mg}$; veículo (vehicle) - $1.000 \mathrm{~g}$.

5 Composição por kg de produto (Composition for product kg): I - $1.500 \mathrm{mg}$; Co $-1.000 \mathrm{mg} ; \mathrm{Cu}-10.000 \mathrm{mg} ; \mathrm{Zn}-100.000 \mathrm{mg} ; \mathrm{Fe}-100.000 \mathrm{mg} ; \mathrm{Mn}-40.000 \mathrm{mg}$; veículo (vehicle): $1.000 \mathrm{~g}$.

rações foi feito diariamente. A conversão alimentar foi calculada pela relação do consumo com o ganho.

Ao 35 dia de idade dos leitões, selecionou-se um animal com peso mais próximo da média de cada unidade experimental para ser abatido, totalizando sete animais por tratamento. Dos animais abatidos foram coletados órgãos como baço, pâncreas, fígado, rins e intestino delgado para pesagem e mensuração do comprimento do intestino delgado, além de segmentos intestinais para confecção de lâminas histológicas para mensuração da altura de vilosidades, profundidade de criptas e relação vilosidade:cripta.

O intestino delgado dos leitões foi dissecado e secções transversais de $2 \mathrm{~cm}$ do duodeno, jejuno e íleo foram coletadas segundo descrição anatômica de Nickel et al. (1973). As amostras foram imersas em solução fixadora (solução de Bouin) por 24 horas. Em seguida, foram lavadas e transferidas para solução de álcool etílico a $70 \%$ até a confecção das lâminas histológicas. Depois de desidratados, os segmentos intestinais foram recortados em frag- 
Tabela 3 - Composições centesimal dos ingredientes e nutricional das dietas experimentais utilizadas na fase pré-inicial 2 (36 a 49 dias) Table 3 - Ingredient percentage and nutritional compositions of the experimental diets in the pre-starter phase 2 (36 to 49 days)

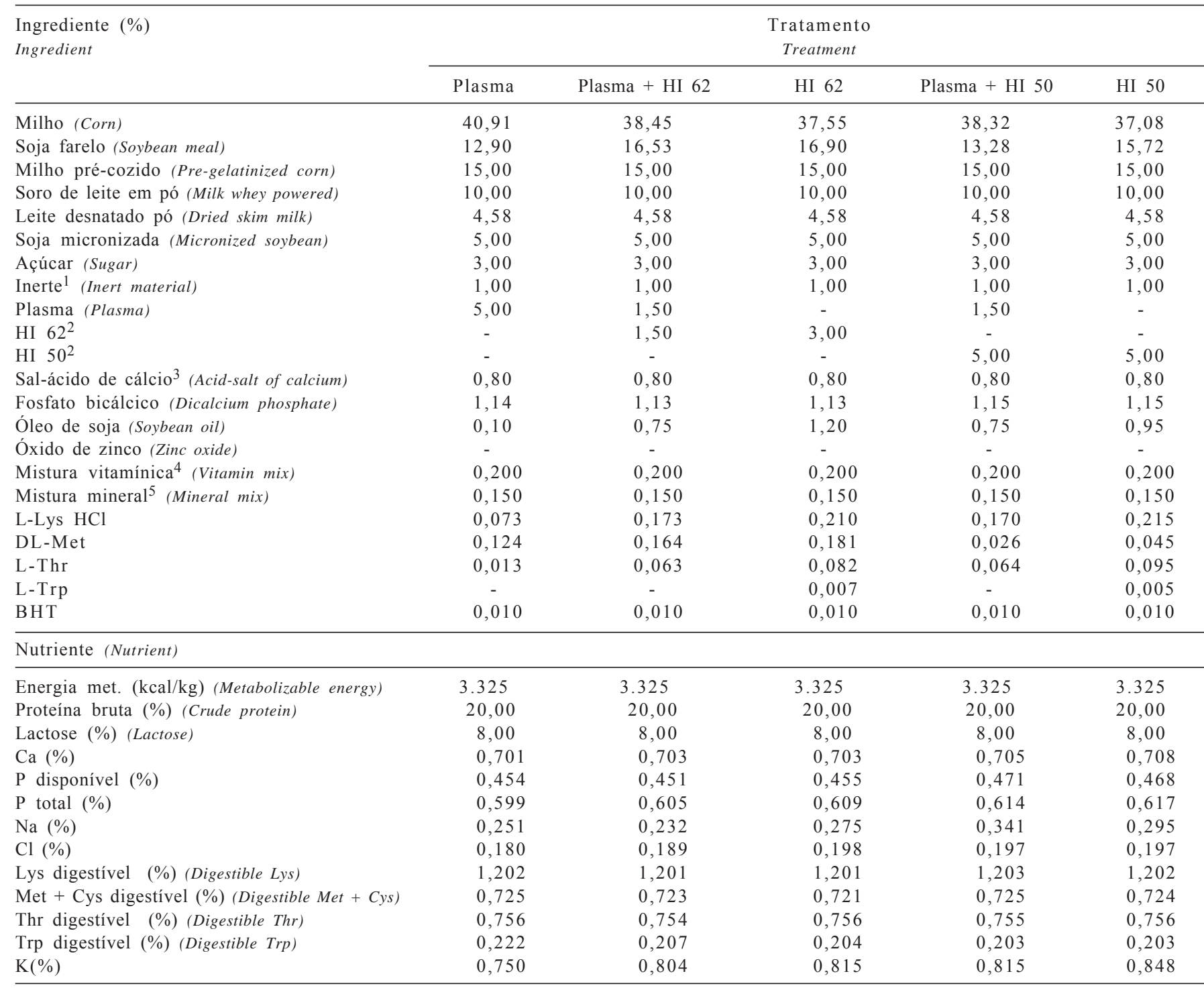

1, 2, 3, 4 Idem Tabela 2 (same Table 2).

mentos de cerca de $1 \mathrm{~cm}$, diafanizados em benzol e incluídos em parafina. Utilizando-se micrótomo, foram produzidas seções com $7 \mu \mathrm{m}$ de espessura, as quais foram coletadas de modo que, entre uma seção e a subseqüente, fossem eliminadas no mínimo 30 seções. As lâminas histológicas foram preparadas no laboratório de Histologia do Departamento de Veterinária da Universidade Federal de Viçosa. As medidas de altura de vilosidade e profundidade de cripta foram realizadas no Laboratório de Nutrição Animal do Departamento de Zootecnia da Universidade Federal de Viçosa, por meio do analisador de imagem "Imagepro Plus 1.3.2" (1994) e microscópio óptico. Para cada lâmina foram selecionadas e medidas 30 vilosidades e 30 criptas. Quatro valores extremos foram descartados para análise estatística, de modo que a média de cada lâmina foi constituída de 26 medidas.
Os dados foram submetidos à análise de variância utilizando-se o programa SAEG (UFV, 1999) e as médias comparadas pelo teste de Student-Newman-Keuls utilizando-se o peso ao abate como covariável, a $5 \%$ de probabilidade.

\section{Resultados e Discussão}

Não houve efeito significativo $(\mathrm{P}>0,05)$ dos tratamentos sobre as características de peso corporal, consumo médio de ração, ganho de peso médio diário e conversão alimentar em nenhum dos períodos analisados (Tabela 4). Os resultados indicaram possibilidade da utilização do HI 62 e HI 50 em substituição total ao plasma, sem prejuízo significativo no desempenho. Por outro lado, não houve efeito aditivo da associação do HI 62 e/ou HI 50 com o plasma. 
Semelhança entre os tratamentos também foi observada por Torrallardona et al (2004), em duas avaliações, quando compararam por 14 dias dietas contendo HI e plasma, não havendo diferença estatística para ganho de peso diário no período experimental e ao final de mais 27 dias experimentais.

Similaridade de desempenho do HI com outras fontes protéicas também foi apontada por outros pesquisadores. Ji (2004) avaliou diversas fontes protéicas de alta qualidade e comparou o desempenho de leitões durante três semanas consumindo dietas com farinha de peixe ( $6 \%$ ) em comparação a dietas com plasma (3,5\%), com HI 50 (2,5 e 3,5\%), plasma e HI $50(2,5+2,5 \%)$ e HI $30(5 \%)$. Todas as dietas tiveram efeitos semelhantes sobre o consumo de ração e o ganho de peso; não houve diferença estatística, à exceção da dieta com farinha de peixe, que apresentou valores inferiores às demais. A conversão alimentar também não diferiu entre as dietas com plasma ou HI 50.

Scandolera (2004), comparando consumo de ração e ganho de peso em leitões de 21 a 49 dias de idade alimentados com dietas contendo farelo de soja, leite em pó integral com ou sem HI e hidrolisado de levedura, também não observou diferença significativa entre as fontes protéicas. Angulo et al. (2001) avaliaram o desempenho de leitões alimentados com HI, plasma e farinha de peixe durante 13 dias pós-desmame e mais 27 dias subseqüentes sob dieta padrão. Esses pesquisadores observaram que a inclusão do HI na fase pré-inicial não resultou em alteração significativa de consumo, enquanto o ganho de peso de letões alimentados com HI ou plasma foi idêntico. Ao final do período inicial, no qual se forneceu uma dieta comum, suínos alimentados com dieta com HI no período anterior mostraram maior peso corporal final (1 kg mais) superior $(\mathrm{P}<0,05)$ ao daqueles alimentados com farinha de peixe.

Estas informações contradizem as de outros autores, como Borda (2004), que comparou dietas pós-desmame com inclusões de plasma (4\%) e HI $62(5 \%)$ e constatou que leitões alimentados com HI 62 apresentaram maior apetite, com maior atração pelo alimento, o que ocasionou maior competição no primeiro consumo de ração. Esse potencial de consumo em favor do HI 62 foi confirmado pela diferença de consumo nos primeiros 7 (758 vs $493 \mathrm{~g} / \mathrm{dia}$ ) e 14 dias (962 vs $611 \mathrm{~g} / \mathrm{dia}$ ) experimentais. No entanto, apenas na primeira semana houve maior ganho de peso diário significativo. O mesmo efeito sobre o consumo foi observado por Lindemann et al. (1998) ao investigarem a inclusão de $6 \%$ de HI em dietas para leitões. Zimmermann et al. (1997) também observaram melhora no consumo em leitões alimentados com dietas com HI. Johnston et al. (2000, 2003), avaliando o consumo voluntário e o desempenho de porcas em lactação alimentadas com dietas contendo dois níveis de HI (1,5 e 3\%), observaram tendência de aumento de consumo mas nenhuma influência sobre o desempenho da leitegada.

Considerando o plasma como estimulador de consumo, como comprovado por Butolo et al., (1999) quando avaliaram inclusões de até $7,5 \%$ de plasma em dietas para leitões e observaram resposta linear no consumo de ração, nota-se que tanto plasma quanto HI possuem capacidade semelhante como potencializadores de consumo.

DeRouchey et al. (2000) compararam o desempenho de leitões de 0 a 14 dias pós-desmama alimentados com dietas contendo $5 \%$ de inclusão de HI 30 ou plasma e não encontraram diferença entre os tratamentos.

Por outro lado, Koehler et al. (1998) registraram melhorias marginais de consumo e ganho de peso em leitões alimentados com 2,5\% de HI, que foram ainda melhorados pela adição de $4 \%$ de plasma. Por sua vez, Bregendahl et al. (1998), trabalhando com leitões desmamados aos 11 a 14 dias de idade, avaliaram dietas contendo 0 e $5 \%$ de plasma ou HI durante duas semanas em ambientes limpo e sujo. Os autores observaram aumento no GPMD e CRMD nos animais alimentados com plasma em relação aos alimentados com HI na primeira semana de avaliação. No entanto, não houve diferença na segunda semana.

$\mathrm{Na}$ avaliação de um ingrediente alternativo na alimentação de suínos, muitas vezes a intenção não é necessariamente determinar se há vantagem nutricional, mas sim, determinar se o ingrediente proporciona comparável desempenho em relação à dieta referência (Lindemann et al., 2000). Neste sentido, os resultados deste estudo indicam que leitões alimentados com dietas formuladas com HI 62 e HI 50 possuem desempenho comparável àqueles alimentados com plasma.

As dietas com HI em substituição parcial ou total ao plasma não influenciaram $(\mathrm{P}>0,05)$ o peso absoluto e relativo de baço, pâncreas, fígado, rins e intestino delgado de leitões abatidos aos 35 dias de idade (Tabela 5). Essa constatação aponta para a não confirmação da possível alteração no peso de vísceras com a incorporação de HI à dieta. A hipótese de alteração na atividade enzimática com a incorporação de diferentes fontes protéicas nas dietas foi avaliada por Ji (2004), que comparou atividade de pepsina, lipase, amilopepsina, tripsina e chimotripsina em leitões alimentados com dietas contendo plasma e/ou HI e não registrou diferenças.

Scandolera (2004) encontrou similaridade entre os pesos absolutos e relativos de pâncreas de leitões alimentados com dietas contendo HI em relação a outras fontes protéicas como farelo de soja e proteína isolada de soja. 
Tabela 4 - Peso corporal, consumo de ração médio diário (CRMD), ganho de peso médio diário (GPMD) e conversão alimentar (CA) de leitões alimentados com dietas contendo plasma e/ou HI 62 e/ou HI 50

Table 4 - Body weight, average daily feed intake (ADFI), average daily weight gain (ADWG), feed:gain ratio ( $F: G)$ of piglets fed diets with plasma and/ or HI 62 and/or HI 50

\begin{tabular}{|c|c|c|c|c|c|c|}
\hline \multirow[t]{2}{*}{ Item } & \multicolumn{5}{|c|}{$\begin{array}{c}\text { Tratamento } \\
\text { Treatment }\end{array}$} & \multirow[t]{2}{*}{$\mathrm{CV}(\%)$} \\
\hline & Plasma & Plasma + HI 62 & HI 62 & Plasma + HI 50 & HI 50 & \\
\hline \multicolumn{7}{|l|}{ Peso corporal $(\mathrm{kg})$} \\
\hline \multicolumn{7}{|l|}{ Body weight } \\
\hline 21 dias & 5,57 & 5,52 & 5,54 & 5,52 & 5,56 & 1,02 \\
\hline 35 dias & 9,26 & 9,25 & 8,82 & 8,78 & 8,66 & 6,34 \\
\hline \multirow[t]{2}{*}{49 dias } & 15,70 & 15,56 & 15,08 & 15,03 & 14,94 & 7,74 \\
\hline & \multicolumn{5}{|c|}{21 a $35 \mathrm{~d}$} & \\
\hline CRMD (g/dia) (ADFI) & 327 & 318 & 291 & 290 & 268 & 15,7 \\
\hline GPMD (g/dia) (ADWG) & 263 & 266 & 234 & 236 & 221 & 15,6 \\
\hline \multirow[t]{2}{*}{$\mathrm{CA}(\mathrm{g} / \mathrm{g})(F: G)$} & 1,25 & 1,18 & 1,23 & 1,25 & 1,24 & 13,2 \\
\hline & \multicolumn{5}{|c|}{36 a 49 d } & \\
\hline CRMD (g/dia) (ADFI) & 658 & 680 & 592 & 629 & 624 & 11,6 \\
\hline GPMD (g/dia) (ADWG) & 450 & 447 & 431 & 439 & 439 & 11,6 \\
\hline \multirow[t]{2}{*}{$\mathrm{CA}(\mathrm{g} / \mathrm{g})(F: G)$} & 1,47 & 1,54 & 1,40 & 1,43 & 1,42 & 9,07 \\
\hline & \multicolumn{5}{|c|}{21 a 49 d } & \\
\hline CRMD (g/dia) (ADFI) & 493 & 499 & 441 & 460 & 446 & 11,0 \\
\hline GPMD (g/dia) (ADWG) & 360 & 355 & 338 & 338 & 329 & 11,8 \\
\hline $\mathrm{CA}(\mathrm{g} / \mathrm{g})(F: G)$ & 1,36 & 1,40 & 1,31 & 1,36 & 1,35 & 7,58 \\
\hline
\end{tabular}

HI 62, HI 50 = hidrolisados de mucosa intestinal de suínos com 62 e 50\% de PB, respectivamente.

HI 62, HI $50=$ hydrolyzed of intestinal mucosa of swine with 62 and $50 \%$ of CP, respectively.

Os resultados de altura de vilosidades, profundidade de criptas e relação vilosidade:cripta do duodeno, jejuno e íleo de leitões aos 35 dias de idade, alimentados com plasma sangüíneo e/ou HI 62 e/ou HI 50 estão dispostos nas Tabela 6.

Não foram observadas alterações $(\mathrm{P}>0,05)$ nas medidas de vilosidades e criptas e na relação entre ambas para as porções intestinais de duodeno, jejuno e íleo. Além de não apresentar diferenças significativas, os tratamentos não foram capazes de minimizar os efeitos pós-desmame sobre a estrutura intestinal; os valores de relação vilo:cripta foram inferiores aos comumente encontrados na literatura, como aqueles compilados por Pluske (2001).

Esses dados seguem a mesma tendência dos apontados por Torrallardona et al (2004), que compararam o comprimento de vilos jejunais de leitões alimentados com plasma e HI e constataram não haver diferenças entre os tratamentos, que por sua vez foram superiores a dieta contendo apenas farelo de soja. No mesmo sentido, Scandolera (2004) também não observou diferença significativa quanto as variáveis morfológicas de duodeno e jejuno de leitões alimentados com HI $50(3,5 \%)$ em relação a outras fontes protéicas. Os resultados deste experimento contrariam os apresentados por Borda (2004), que observou diferença significativa de vilos e criptas na comparação de dietas com
HI 62 e plasma, de modo que o primeiro tratamento apresentou os maiores valores para ambas as variáveis.

Ji (2004) não observou diferença significativa na morfologia intestinal do duodeno quando comparou dietas com plasma e/ou HI 50, no entanto, observou maiores valores de altura de vilos em animais alimentados com dieta contendo HI em comparação à mesma inclusão de plasma.

As propriedades do plasma que permitem que se mantenha a integridade de mucosa foram levantadas por Yi et al. (2005). Segundo esses autores, componentes como fator de crescimento epidermal e IGF podem ser tróficos para as vilosidades do intestino delgado; além disso, o alto conteúdo de glutamina + glutamato (aproximadamente $11,2 \%$ ) e imunoglobulina (aproximadamente $25 \%$ ) podem contribuir para diminuir a atrofia de vilos e o rompimento da morfologia intestinal. Anteriormente Bosi et al. (2004) registraram a capacidade do plasma como melhorador de desempenho e proteção contra infecção de E. coli K88 pela mantença da integridade intestinal e modulação da resposta imune em suínos.

Uma vez que não houve diferença entre os tratamentos quanto aos parâmetros de integridade intestinal, pode-se afirmar que os produtos HI 62 e HI 50 também possuem características nutricionais positivas, no entanto, não promovem efeito aditivo quando fornecidos em conjunto ao plasma. 
Tabela 5 - Pesos absoluto e relativo de órgãos e comprimento de intestino delgado de leitões aos 35 dias de idade alimentados com dietas contendo plasma e/ou $\mathrm{HI} 62$ e/ou HI 50

Table 5 - Absolute and relative weights of organs and length of small intestine of piglets at 35 days of age fed diets with plasma and/or HI 62 and/or HI 50

\begin{tabular}{|c|c|c|c|c|c|c|}
\hline \multirow[t]{2}{*}{ Item } & \multicolumn{5}{|c|}{$\begin{array}{c}\text { Tratamento } \\
\text { Treatment }\end{array}$} & \multirow[t]{2}{*}{$\mathrm{CV}(\%)$} \\
\hline & Plasma & Plasma + HI 62 & HI 62 & Plasma + HI 50 & HI 50 & \\
\hline \multicolumn{7}{|l|}{ Peso absoluto (Absolut weight) } \\
\hline Peso médio abate ( $\mathrm{kg})$ (Average weight at slaughter) & 9,32 & 9,33 & 8,69 & 9,06 & 8,83 & 7,20 \\
\hline Baço (g) (Spleen) & 20,00 & 16,86 & 15,86 & 18,71 & 16,43 & 15,6 \\
\hline Pâncreas (g) (Pancreas) & 21,00 & 20,29 & 17,43 & 21,71 & 21,00 & 12,0 \\
\hline Fígado (g) (Liver) & 273,6 & 275,0 & 254,9 & 279,9 & 274,1 & 9,82 \\
\hline Rins (g) (Kidneys) & 54,71 & 52,29 & 47,14 & 52,00 & 52,43 & 14,2 \\
\hline Intestino delgado (g) (Small intestine) & 787,4 & 753,3 & 732,0 & 747,3 & 704,4 & 11,8 \\
\hline Intestino delgado (m) (Small intestine) & 13,48 & 12,79 & 12,07 & 13,16 & 12,79 & 6,77 \\
\hline \multicolumn{7}{|l|}{ Peso relativo $^{1}$ (Relative weight) } \\
\hline Baço (\%) (Spleen) & 0,21 & 0,18 & 0,18 & 0,20 & 0,18 & 15,9 \\
\hline Pâncreas (\%) (Pancreas) & 0,22 & 0,21 & 0,20 & 0,24 & 0,24 & 12,1 \\
\hline Fígado (\%) (Liver) & 2,94 & 2,96 & 2,93 & 3,07 & 3,08 & 9,08 \\
\hline Rins (\%) (Kidneys) & 0,58 & 0,55 & 0,54 & 0,57 & 0,59 & 13,8 \\
\hline Intestino delgado (\%) (Small intestine) & 8,52 & 8,05 & 8,43 & 8,45 & 8,04 & 11,2 \\
\hline
\end{tabular}

HI 62, HI 50 = hidrolisados de mucosa intestinal de suínos com 62 e 50\% de PB, respectivamente.

HI 62, HI $50=$ hydrolyzed of intestinal mucosa of swine with 62 and $50 \%$ of CP, respectively.

${ }^{1}$ Proporcional ao peso de abate (Proportional to the slaughter weight).

Tabela 6 - Altura de vilosidades, profundidade de criptas e relação vilosidade:cripta do duodeno, jejuno e íleo de leitões aos 35 dias de idade alimentados com dietas contendo plasma e/ou HI 62 e/ou HI 50

Table 6 - Villus height, crypts depth and villus:crypts ratio of duodenum, jejunum and ileum of piglets at 35 days of age fed diets with plasma and/or HI 62 and/or HI 50

\begin{tabular}{|c|c|c|c|c|c|c|}
\hline \multirow[t]{2}{*}{ Item } & \multicolumn{5}{|c|}{$\begin{array}{c}\text { Tratamento } \\
\text { Treatment }\end{array}$} & \multirow[t]{2}{*}{$\mathrm{CV}(\%)$} \\
\hline & Plasma & Plasma + HI 62 & HI 62 & Plasma + HI 50 & HI 50 & \\
\hline & \multicolumn{5}{|c|}{ Duodeno (Duodenum) } & \\
\hline Vilosidades $(\mu \mathrm{m})$ (Villus) & 350,87 & 376,16 & 390,43 & 318,64 & 331,76 & 18,1 \\
\hline Criptas $(\mu \mathrm{m})$ (Crypts) & 352,99 & 380,55 & 387,00 & 375,20 & 409,95 & 18,1 \\
\hline \multirow[t]{2}{*}{ Relação vilo:cripta Villus:crypt ratio } & 0,99 & 0,99 & 1,01 & 0,85 & 0,81 & 26,8 \\
\hline & \multicolumn{5}{|c|}{ Jejuno (Jejunum) } & \\
\hline Vilosidades $(\mu \mathrm{m})$ (Villus) & 363,58 & 392,83 & 354,76 & 396,35 & 385,93 & 12,9 \\
\hline Criptas $(\mu \mathrm{m})$ (Crypts) & 296,23 & 276,16 & 266,34 & 247,77 & 274,18 & 18,5 \\
\hline \multirow[t]{2}{*}{ Relação vilo:cripta (Villus:crypt ratio) } & 1,23 & 1,42 & 1,33 & 1,60 & 1,41 & 24,5 \\
\hline & \multicolumn{5}{|c|}{ Íleo (Ileum) } & \\
\hline Vilosidades $(\mu \mathrm{m})$ (Villus) & 295,85 & 370,04 & 310,57 & 322,70 & 310,55 & 26,4 \\
\hline Criptas $(\mu \mathrm{m})$ (Crypts) & 262,07 & 222,69 & 206,47 & 215,60 & 210,48 & 25,1 \\
\hline Relação vilo:cripta (Villus:crypt ratio) & 1,13 & 1,66 & 1,50 & 1,50 & 1,48 & 22,9 \\
\hline
\end{tabular}

HI 62, HI 50 = hidrolisados de mucosa intestinal de suínos com 62 e 50\% de PB, respectivamente.

HI $62, \mathrm{HI} 50=$ hydrolyzed of intestinal mucosa of swine with 62 and $50 \%$ of CP, respectively.

\section{Conclusões}

A substituição total ou parcial do plasma pelo hidrolisado da mucosa intestinal de suínos com 62 ou $50 \%$ de proteína na dieta de leitões de 21 a 49 dias de idade não tem efeito significativo sobre o desempenho, a morfologia intestinal, o peso absoluto e relativo de baço, fígado, rins e o peso e comprimento de intestino delgado.

As formulações de dietas utilizando HI 62 e HI 50 são alternativas a dietas de alto valor nutricional para leitões nas fases pós-desmame. Esses produtos podem substituir parcial ou totalmente a inclusão de plasma em dietas para leitões. 


\section{Agradecimento}

À Metachem Indústria e Comércio Ltda., pelo fornecimento dos hidrolisados de mucosa intestinal de suínos, Palbio $^{\circledR}$, e ao Conselho Nacional de Desenvolvimento Científico e Tecnológico (CNPq), pela concessão da bolsa de estudo.

\section{Literatura Citada}

ANGUlo, E.; CÓRdobA, X.; TORRAllardonA, D. Porcine digestible peptides improve feed intake and performance of weaning pigs. In: BRUFAU, J. (Ed.). Feed manufacturing in the Mediterranean region. Improving safety: from feed to food. Zaragoza: CIHEAM-IAMZ, 2001. p.161-164.

BERTOL, T.M.; MORES, N.; FRANKE, M.R. Substituição parcial do farelo de soja por soja integral extrusada na dieta de leitões desmamados. Revista Brasileira de Zootecnia, v.30, n.3, p.744-752, 2001

BORDA, E. Effect of Palbio PDP (Palbio 62 SP) on the productive and histological parameters of piglets at the weaning stage. Barcelona: Bioiberica Nutrition Care, 2004. 52p. (Report).

BOSI, P.; CASINI, L.; FINAMORE, A. et al. Spray-dried plasma improves growth performance and reduces inflammatory status of weaned pigs challenged with enterotoxigenic Escherichia coli K88. Journal of Animal Science, v.82, p.1764-1772, 2004

BREGENDAHL, K.; SPARKS, J.C.; BASSAGANYA, J. et al. Effect of spray-dried plasma and dried porcine solubles on the growth performance of weanling pigs raised in different health-status environments. Iowa: Iowa State University Extension, 1998. 3p. (ISU Swine Research Report, ASL-R1554)

BUTOLO, E.A.F.; MIYADA, V.S.; PACKER, I.U. et al. Uso de plasma suíno desidratado por spray-dryer na dieta de leitões desmamados precocemente. Revista Brasileira de Zootecnia, v.28, n.3, p.326-333, 1999.

CÓRDOBA, X.; BASSA, J.; TORRALLARDONA, D. Efecto de la inclusión de peptidos digestibles de porcino en la nutrición de lechones Anaporc, v.20, n.205, p.148-167, 2000.

DeROUCHEY, J.M.; TOKACH, M.D.; NELSSEN, J.L. et al. Effects of irradiation processing of specialty protein products on nursery pig performance. Manhattan: Kansas State University. Swine Day. 2000 p.66-69.

FIGUEREDO, A.N.; MIYADA, V.S., UTIYAMA, C.E. et al. Ovo em pó na alimentação de leitões recém-desmamados. Revista Brasileira de Zootecnia, v.32, n.6, p.1901-1911, 2003.

JI, C. Evaluation of DPS supplement in early-weaned pig diets. Sioux City: Nutra-Flo ${ }^{\circledR}$ Company, 2004. 4p. (Special Research Report).

JOHNSTON, L.J.; PETTIGREW, J.E.; BAIDOO, S.K. et al. Efficacy of sucrose and milk chocolate product or dried porcine solubles to increase feed intake and improve performance of lactating sows. Journal of Animal Science, v.81, p.2475-2481, 2003.

JOHNSTON, L.J.; BAIDOO, S.K.; SHURSON, G.C. et al. Effect of dried porcine solubles on performance of lactating sows. Journal of Animal Science, v.78 (Suppl. 1), p.176 (Abstr.), 2000 .
KOEHLER, D.D.; SHURSON, G.C.; WHITNEY, M.H. Effect of spray dried porcine solubles, with and without spray dried porcine plasma, on growth performance of weaned pigs. Journal of Animal Science, v.76 (Suppl. 1), p.180 (Abstr.), 1998.

LINDEMANN, M.D.; van de LIGT, J.L.G., MONEGUE, H.J. et al. Evaluation of dried porcine solubles (DPS) as a feed ingredient for weanling pigs. Journal of Animal Science, v.76 (Suppl. 1), p.181 (Abstr.), 1998.

LINDEMANN, M.D.; CROMWELL, G.L.; MONEGUE, H.J. et al Feeding value of an enzymatically digested protein for earlyweaned pigs. Journal of Animal Science, v.78, p.318-327, 2000 .

NICKEL, R.; SCHUMMER, A.; SEIFERLE, E. The viscera of the domestic mammals. Berlin: Verlag Paul Parey, 1973. s.p.

NUTRA-FLO COMPANY. [2004]. Small peptides protein increase amino acid absorption and production of pancreatic hormones. (Technical Bulletin 21). Disponível em: <www.NFProtein.com.> Acesso em: 30/5/2006.

PLUSKE, J.R. Morphological and functional changes in the small intestine of the newly-weaned pig. In: [S.I.] Gut environment of pigs. Nottingham University Press, 2001. p.1-28.

ROSTAGNO, H.S. Tabelas brasileiras para aves e suínos. Composição de alimentos e exigências nutricionais. 2.ed. Viçosa, MG: Universidade Federal de Viçosa, 2005. 186p.

SCANDOLERA, A.J. Hidrolisado protéico do conteúdo celular de levedura, proteína isolada de soja, hidrolisado protéico de mucosa intestinal de suínos em associação ao leite em pó integral para leitões recém-desmamados. Jaboticabal: Universidade Estadual Paulista, 2004. 77p. Tese (Doutorado em Zootecnia) - Universidade Estadual Paulista, 2004.

SCANDOLERA, A.J.; THOMAZ, M.C.; KRONKA, R.N. et al. Efeitos de fontes protéicas na dieta sobre a morfologia intestinal e o desenvolvimento pancreático de leitões recém-desmamados. Revista Brasileira de Zootecnia, v.34, n.6, p.2355-2368, 2005 (supl.)

TEIXEIRA, A.O.; LOPES, D.C.; FERREIRA, V.P.A. et al. Utilização de enzimas exógenas em dietas com diferentes fontes e níveis de proteína para leitões na fase de creche. Revista Brasileira de Zootecnia, v.34, n.3, p.900-906, 2005.

TORRALLARDONAA, D.; CÓRDOBAB, X.; ANGULOC, E. Effects of high quality animal proteins on performance and gut morphology and microbiology of weaning piglets. Animal Research, v.53, p.335-339, 2004.

UNIVERSIDADE FEDERAL DE VIÇOSA - UFV. Sistema para Análises Estatísticas e Genética - SAEG. (Versão 8.0) Viçosa, MG: Universidade Federal de Viçosa, 1999.

YI, G.F.; CARROLL, J.A.; ALLEE, G.L. et al. Effect of glutamine and spray-dried plasma on growth performance, small intestinal morphology, and immune responses of Escherichia coli $\mathrm{K} 88+-$ challenged weaned pigs. Journal of Animal Science, v. 83 , p.634-643, 2005.

ZIMMERMAN, D.R.; SPARKS, J.C.; CAIN, C.M. Carry-over responses to an intestinal hydrolysate in weanling pig diets. Journal of Animal Science, v.75 (Supp1. 1), p.71 (Abstr.), 1997.

ZIMMERMAN, D.; SPARKS, C. Evaluation of a byproduct from hydrolyzed porcine small intestines as an ingredient in pig starters. Iowa: Iowa State University Extension, 1996. 7p. (ISU Swine Research Report, ASL-R1365).

Recebido: 17/7/2006 Aprovado: 9/7/2007 